\title{
ВОЗРАСТНЫЕ ОСОБЕННОСТИ РЕОРГАНИЗАЦИИ ЦЕРЕБРАЛЬНОЙ ГЕМОДИНАМИКИ И МЕТАБОЛИЗМА У БОЛЬНЫХ ИШЕМИЧЕСКИМ ИНСУЛЬТОМ В ВОССТАНОВИТЕЛЫНЫЙ ПЕРИОД
}

\author{
${ }^{1}$ С.М.Кузнецова*, ${ }^{1}$ В.В.Кузнецов, ${ }^{2}$ С.Г.Мазур
}

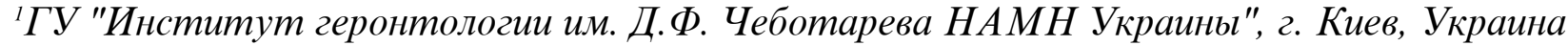

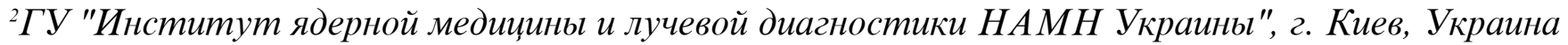

В статье представлены результаты комплексного обследования больных среднего и пожилого возраста (282 человека), перенесших ишемический атеротромботический инсульт. Установлено, что у больных среднего возраста по сравнению с контрольной группой соответствующего возраста более выражены изменения церебральной гемодинамики, чем у больных пожилого возраста. В то же время, для больных пожилого возраста характерно более интенсивное снижение, чем у больных среднего возраста, содержания основных метаболитов головного мозга (NAA, $\mathrm{Cr}$ ). Возрастные особенности отмечены и в структуре взаимосвязей церебральной гемодинамики и метаболизма. Ключевые слова: ишемический атеротромботический инсульт, церебральная гемодинамика, метаболизм, возраст

Инсульт относится к высоко инвалидизирующим заболеваниям, что определяет высокую медико-социальную актуальность проблемы реабилитации [3]. Известно, что одним из важных факторов как риска развития, так и течения инсульта является возраст [7]. Это обусловлено тем, что в процессе старения сужается диапазон функциональной активности и компенсаторных возможностей сердечно-сосудистой, нервной, иммунной систем и формируются лимитирующие звенья, предрасполагающие к развитию церебро-васкулярных заболеваний и в частности инсульта [9]. За последнее десятилетие не только увеличивается частота инсульта, но и изменяется возрастная структура заболеваемости инсультом за счет увеличения доли больных среднего возраста. Факторы, обуславливающие "омоложение" инсульта, это повышение уровня психоэмоционального напряжения, неблагоприятная экология, а также повышение количества и расширение спектра вирусных заболеваний которым отводится значительная роль в формировании клеточных механизмов развития атеросклероза [1]. В настоящее время установлено наличие возрастных особенностей патогенетических механизмов клинического оформления и течения инсульта, что определяет необходимость для разработки эффективных реабилитационных мероприятий наряду с общими принципами реабилитации учитывать возрастные особенности метаболической, гемодинамической и морфометрической реорганизации мозга у больных, пе-

\footnotetext{
*e-mail: stroke_kiev@mail.ru
}

ренесших инсульт $[4,14]$.

Важным положением в стратегии реабилитации является ликвидация или уменьшение устойчивого патологического состояния, которое формируется в острый период инсульта, когда на фоне деструктивных процессов, обусловленных ишемией мозга, устанавливаются функционально-биохимические связи между отдельными структурами мозга, направленные на компенсацию нарушенных функций мозга [12]. От структуры и уровня этой острой компенсации в значительной степени зависит исход острого периода и тип постинсультных синдромов. В восстановительный период у больных, перенесших ишемический инсульт, сформировавшиеся "жесткие" и "мягкие" звенья в системе устойчивого патологического состояния тормозят процессы восстановления и формирования новых стереотипов [2].

Тип устойчивого патологического состояния, обусловленного инсультом, определяется многими факторами, такими как локализация и размер очага, конституциональными особенностями морфо-функциональной организации мозга, наличием сопутствующих заболеваний и конечно возрастом больных. Для изучения возрастных особенностей механизмов формирования устойчивого патологического состояния, обусловленного инсультом, необходимо знание структуры реорганизации метаболизма мозга, церебральной гемодинамики у больных инсультом в восстановительный период $[6,8]$. 
Цель настоящей работы: изучить у больных среднего и пожилого возраста, перенесших ишемический инсульт, состояние церебральной гемодинамики, метаболизма головного мозга и их взаимоотношений.

Материалы и методы: обследовано 282 пациента среднего $(52,5 \pm 3,8$ года) и пожилого возраста (68,2 22,1 лет), перенесших ишемический инсульт в каротидном бассейне, в восстановительный период (до 1 года после острого периода).

Всем больным проводилось УЗДС исследование сосудов головы и шеи с помощью ультразвуковой установки EN VISOR (PHILIPS) и "Sonoline Elegra" (SIEMENS). Оценивалось: толщина комплекса "интима-медиа" (КИМ) общей сонной артерии (ОСА); степень стеноза; частота выявления и структура атеросклеротических бляшек; диаметры сосудов; скоростные показатели церебральной гемодинамики: линейная систолическая скорость кровотока (ЛССК) и объемная скорость кровотока в интра- и экстракарниальных сосудах каротидного и вертебробазилярного бассейнов. Содержание $\mathrm{N}$-ацетиласпартата (NAA), креатина (Cr), холина (Cho) и лактата в белом веществе лобной области и сером ве- ществе затылочной области головного мозга определялось в относительных единицах методом ${ }^{1} \mathrm{H}$ MPC на томографе $1.5 \mathrm{~T}$ Magnetom Vision Plus (SIEMENS) [11]. Полученные результаты исследований были статистически обработаны на компьютере при помощи стандартного статистического пакета "Microsoft ® Excel 97", "Statistica ${ }^{\circledR}$ for Windows 6.0".

\section{Результаты и обсуждение.}

Анализ состояния церебральной гемодинамики и метаболизма у больных среднего и пожилого возраста, перенесших атеротромботический ишемический инсульт, показал наличие возрастных особенностей механизмов постинсульной реорганизации как гемодинамики так и метаболизма мозга.

Так, для больных среднего возраста характерно значительное снижение скоростных показателей церебральной гемодинамики в сосудах как пораженного, так и интактного каротидного бассейна по сравнению с соответствующими показателями у лиц среднего возраста без цереброваскулярной патологии. У больных пожилого возраста снижение церебральной гемодинамики менее выражено в сосудах пораженного и интактного каротидного бассейна (рисунок 1).

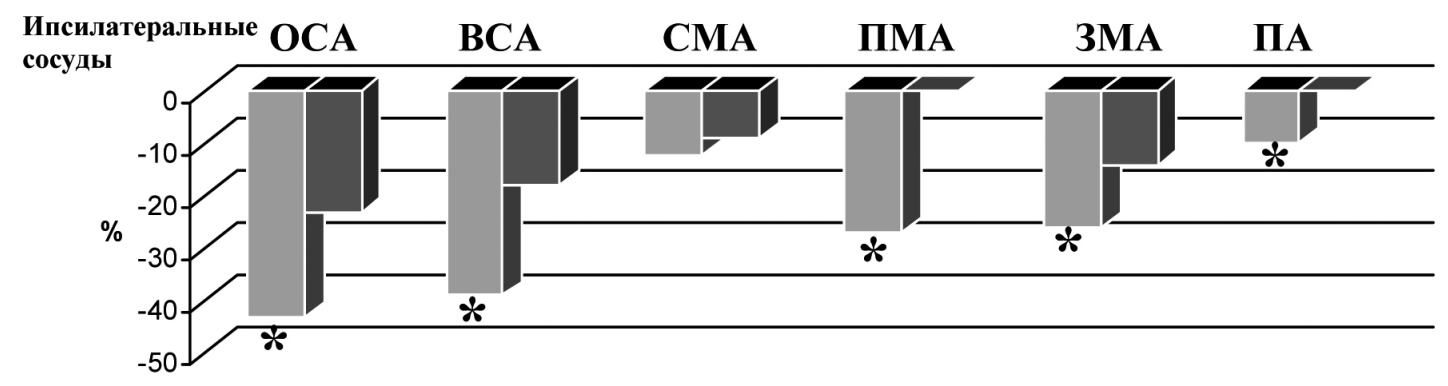

Гетеролатеральные

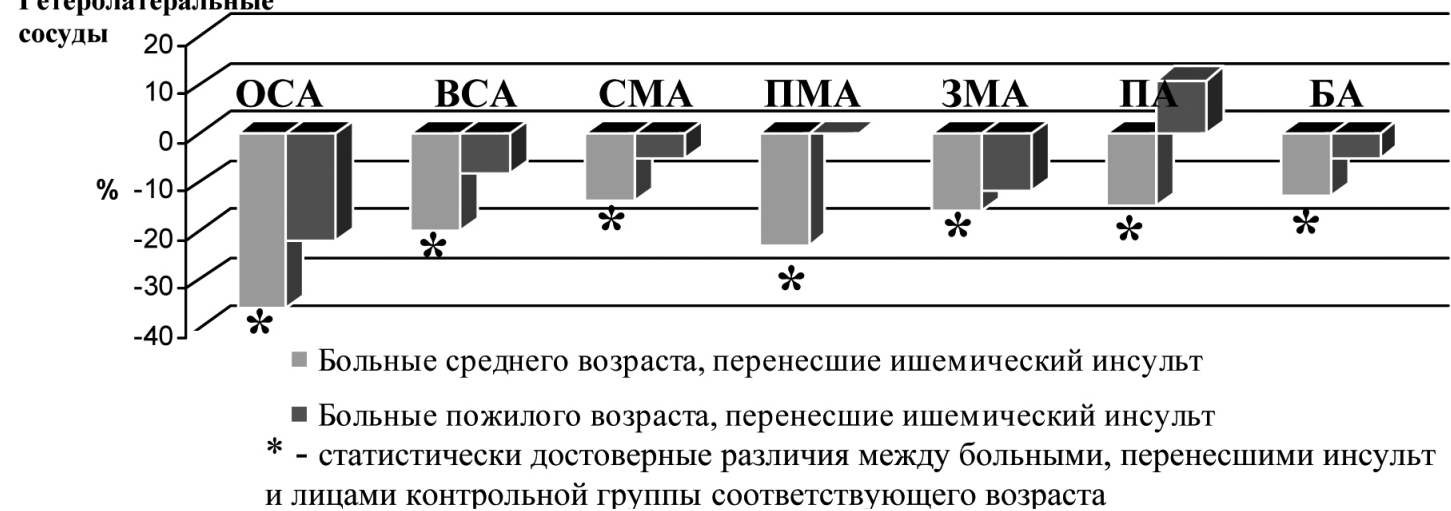

Рис. 1. Степень снижения ЛССК в сосудах каротидного и вертебробазилярного бассейнов у больных среднего и пожилого возраста, перенесших ишемический инсульт, по сравнению с контрольными группами соответствующего возраста. 
Состояние мозгового кровообращения оценивалось также и по показателям структуры атеросклеротических бляшек в сосудах каротидного бассейна. Различают три типа атеросклеротических бляшек - гипоэхогенные, гетерогенные, гиперэхогенные. Наиболее агрессивные и склонные к тромбоэмболизации гипоэхогенные бляшки [5]. У больных среднего возраста более высокая, чем у больных пожилого возраста, частота этого типа атеросклеротических бляшек, что свидетельствует о более агрессивном течении атеросклеротического процесса у больных среднего возраста (рисунок 2).

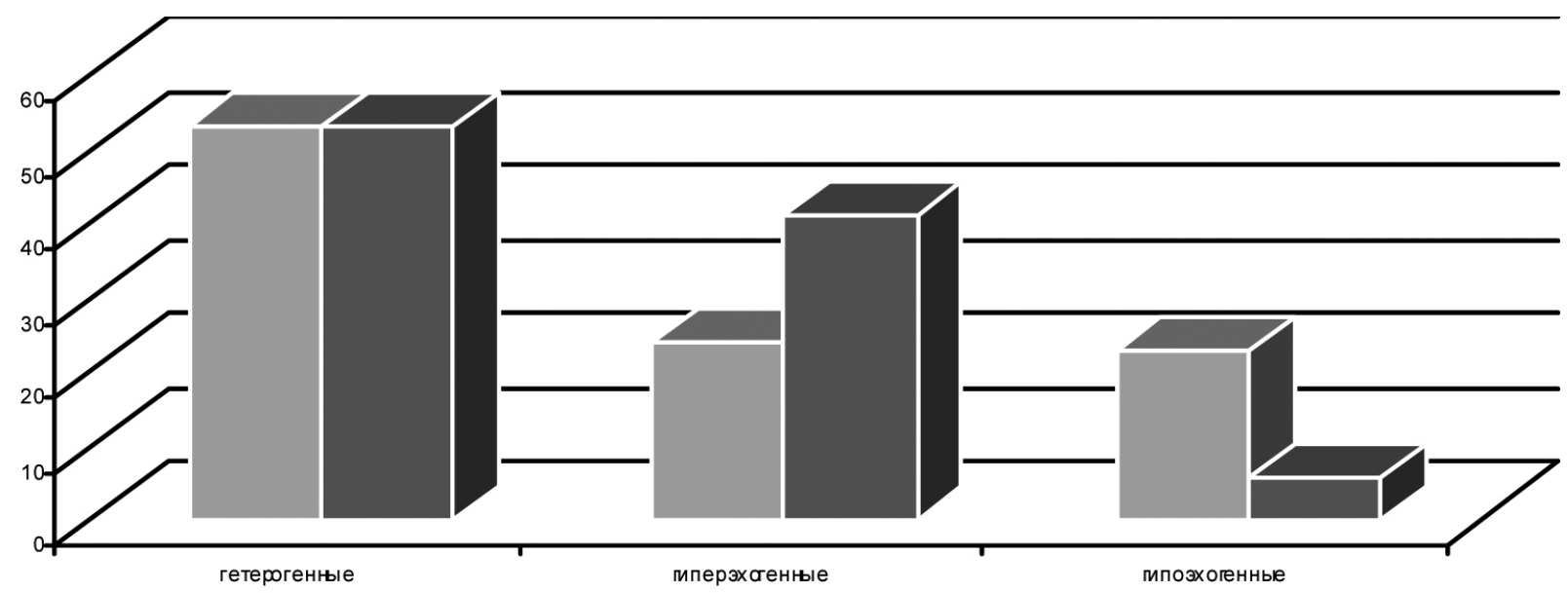

- Больные среднего возраста, перенесшие иш емич еский инсульт

口ольные пожилого возраста, перенесшие иш емич еский инсульт

Рис. 2. Частота различных типов атеросклеротических бляшек у больных среднего и пожилого возраста, перенесших ишемический инсульт.

Учитывая, что в системе реабилитации больных инсультом разного возраста значительное место занимают фармакологические препараты метаболического спектра произведено изучение уровня метаболических процессов по данным магнитно-резонансной

$\mathbf{A}$

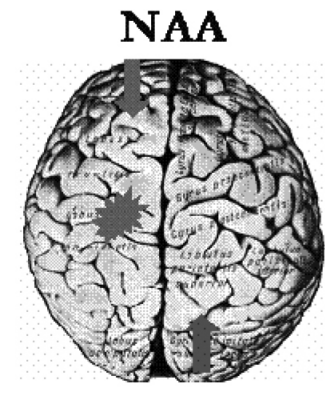

$\mathbf{b}$

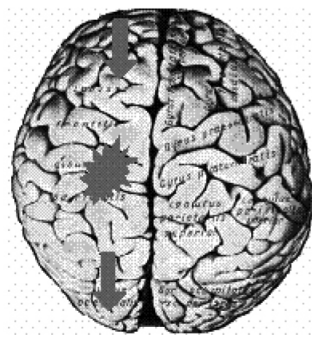

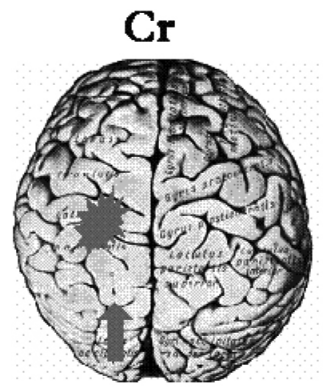

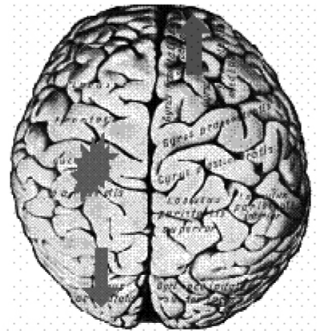

спектроскопии.

Результаты спектрального анализа содержания основных метаболитов в белом и сером веществе свидетельствуют о более выраженных изменениях метаболизма у больных пожилого возраста (рисунок 3).

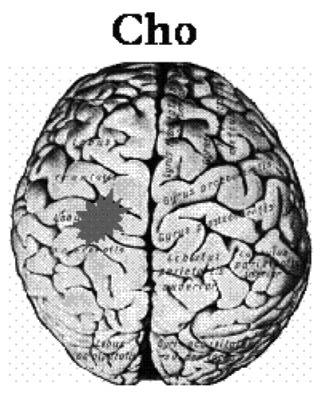

Рис. 3. Изменения содержания основных метаболитов в белом веществе лобной области и сером веществе затылочной области головного мозга у больных среднего (А) и пожилого (Б) возраста, перенесших ишемический инсульт, по сравнению с контрольными группами соответствующих возрастов. 
Так, у больных пожилого возраста снижено содержание NAA, метаболита, характеризующего уровень нейрональной активности и используемого для прогноза течения и исхода инсульта [13], в лобной и затылочной области пораженного полушария, у больных среднего возраста только в лобной области пораженного полушария на фоне компенсаторного повышения содержания NAA в затылочной области интактного полушария. У больных пожилого возраста снижено также содержание $\mathrm{Cr}$ в затылочной области пораженного полушария, в группе больных среднего возраста отмечается повышение содержания $\mathrm{Cr}$ в этой области. У 70\% больных пожилого возраста и у $30 \%$ среднего возраста констатируется наличие лактата в различных участках мозга, что указывает также на наличие более выраженной гипоксии у больных пожилого

\section{A}

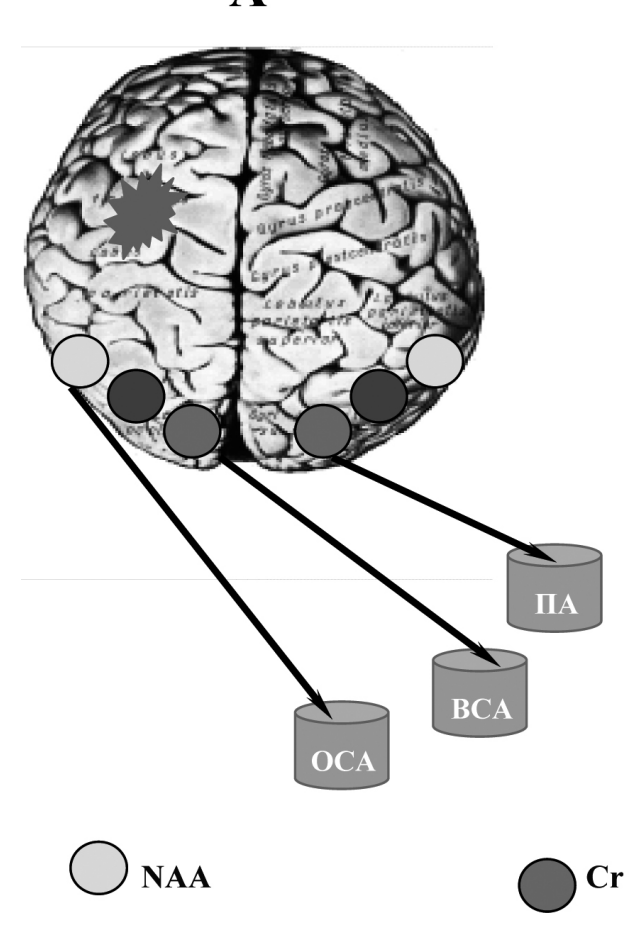

возраста.

Принимая во внимание положение о прямой корреляционной взаимосвязи метаболизма и церебральной гемодинамики, данные о возрастных особенностях изменений содержания основных метаболитов и показателей церебральной гемодинамики, свидетельствующие о более значительном изменении метаболизма мозга на фоне менее выраженного снижения церебральной гемодинамики у больных пожилого возраста характеризуют изменения этих взаимосвязей [10]. Ответ на это казалось бы парадоксальное положение дает анализ взаимосвязи показателей церебральной гемодинамики в сосудах каротидного и вертебро-базиллярного бассейнов (объемная скорость кровотока) с содержанием основных метаболитов у больных двух возрастных групп (рисунок 4).

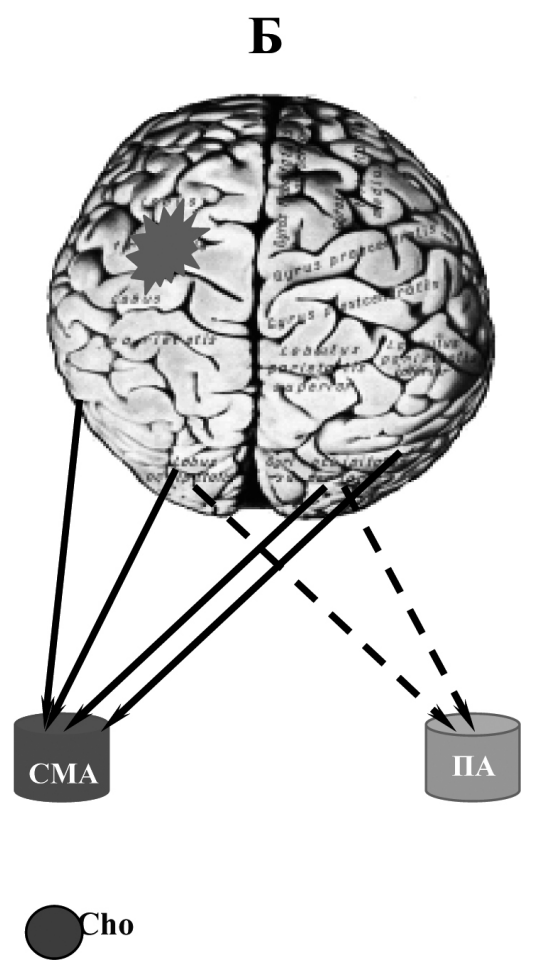

Рис. 4. Структура корреляционных связей (r>0,7) между содержанием метаболитов в сером веществе затылочной области и объемной скоростью кровотока у больных среднего (А) и пожилого (Б) возраста.

Так, у больных среднего возраста содержание основных метаболитов в затылочной области статистически достоверно коррелирует с объемной скоростью кровотока в экстракраниальных сосудах интактного каротидного бассейна, у больных пожилого возраста содержа- ние метаболитов как в интактном, так и в пораженном полушарии преимущественно коррелирует с гемодинамикой в интактной СМА.

Исходя из этих данных следует сделать следующее обобщение: с возрастом у больных инсультом происходят изменения взаимосвя- 
зи метаболизма и гемодинамики, что, возможно, является одним из механизмов, определяющих возрастные особенности реорганизации метаболизма и церебральной гемодинамики у больных инсультом в восстановительный период.

Итак, сравнительный анализ состояния церебральной гемодинамики и метаболизма мозга у больных среднего и пожилого возраста, перенесших атеротромботический ишемический инсульт в каротидном бассейне показал, что у больных среднего возраста в восстановительный период инсульта более выражены изменения церебральной гемодинамики, у больных пожилого возраста более значительно снижение метаболизма мозга (по данным содержания отдельных метаболитов).

Возрастные особенности реорганизации метаболизма и гемодинамики дают основание рекомендовать в системе реабилитации больных среднего возраста, перенесших ишемический инсульт, акцент делать на вазоактивную терапию, у больных пожилого возраста - на метаболическую.

\section{СПИСОК ЛИТЕРАТУРЫ}

1. Alexandrov A.V. Cerebrovascular ultrasound in stroke prevention and treatment. - N.Y.: Blackwell Publishing., 2003. - 267 P.

2. Barker P., Gillard J, Waldman A. Fundamentals of MR Spectroscopy. - Cambridge: Cambridge University Press, 2005. - $260 \mathrm{p}$.

3. Ebrahim S., Harwood R. Stroke. Epidemiology, evidence and clinical practice. - Oxford, 2002. - 305 P. 4. Fiebach J.B., P.D.Schellinger Stroke MRI. Heidelberg: Springer, 2002. - 108 p.

5. Fisher M. Stroke Therapy. - Butterworth Heinemann, 2001.- 397 P.

6. Гудкова В.В., Стаховская Л.В., Шеховцова К.В., Скворцова В.И. Постинсультный период: патофизиологические процессы, клинические проявления и лечение // Фарматека. - 2006. - № 19. - С.38-42

7. Гусев Е.И., Скворцова В.И. Ишемия головного мозга. - М.: Медицина, 2001. - 250 с.

8. Епифанов В.А. Реабилитация больных, перенесших инсульт: М.: Медпресс-информ, 2006. $251 \mathrm{c}$.

\section{ВЫВОДЫ}

1. У больных среднего возраста в восстановительный период инсульта более выраженные изменения церебральной гемодинамики, у больных пожилого возраста - метаболизма.

2. У больных пожилого возраста на уровень метаболизма в затылочной области преимущественно влияет гемодинамика в интракраниальных сосудах пораженного каротидного бассейна (СМА).

3. У больных среднего возраста, перенесших ишемический инсульт, в восстановительный период содержание основных метаболитов коррелирует с уровнем гемодинамики в экстракраниальных сосудах интактного каротидного бассейна.

4. Возрастные особенности метаболизма и церебральной гемодинамики у больных, перенесших ишемический инсульт, свидетельствуют о том, что в системе реабилитации больных пожилого возраста акцент необходимо делать на активизацию метаболических процессов, у больных среднего возраста - на церебральную гемодинамику.

9. Кузнецова С.М. Возрастные аспекты реабилитации постинсультных больных // Медична газета "Здоров'я України". - 2006. - № 23. - С.25

10. Никитин Ю.М., Труханова А.И. Ультразвуковая допплеровская диагностика в клинике - М.: МИК, 2004. - $491 \mathrm{c}$.

11. Скоромец А.А., Ковальчук В.В. Медикаментозная реабилитация пациентов после инсульта // Журнал неврологии и психиатрии. - 2007. - № 2. C. 21-24

12. Суслина 3.А. Варакин Ю.Я. Верещагин Н.В. Сосудистые заболевания головного мозга - Москва.: МЕДпресс-информ, 2006. - 254 с.

13. Суслина 3.А. Ишемический инсульт: принципы лечения в острейшем периоде. // Атмосфера. Нервные болезни. - 2004. - №1. - С.14-18

14. Уордлоу Д. Нейровизуализация при инсульте: достижения и преимущества // Журнал неврологии и психиатрии. - 2000. - № 8. - С. 35-37

15. Фролькис В.В. Старение мозга // Ленинград "Наука".- 1991.- 227 с. 


\title{
SUMMARY
}

\section{AGE-SPECIFIC CHARACTERISTICS OF CEREBRAL HEMODYNAMICS AND METABOLISM REORGANIZATION IN STROKE RECOVERY PERIOD PATIENTS}

\author{
${ }^{1}$ Kuznetsova S.M., ${ }^{1}$ Kuznetsov V.V., ${ }^{2}$ S.Q.Mazur \\ ${ }^{1}$ State institution "D.F. Chebotarev Institute of Gerontology of National Academy of Medical \\ Sciences of Ukraine"
}

${ }^{2}$ State institution "Institute of Radiation Medicine and diagnostics of National Academy of Medical Sciences of Ukraine"

Complex examination results of ischemic atherothrombotic stroke patients of mean and middle age (282 ones) are presented in the article. It was assigned that in mean age patients comparing with control group of corresponding age cerebral hemodynamics changes are more marked than in middle age ones. At the same time in middle age patients is observed more intensive decreasing of main cerebral metabolites (NAA, Cr) than in mean age group. Also there are age-specific characteristics in structure interrelations of cerebral hemodynamics and metabolism reorganization.

Key words: ischemic atherothrombotic stroke, cerebral hemodynamics, metabolism, age

\section{XÜLASə}

\section{IŞEMIK İNSULTLU XəSTӘLӘRDӘ BӘRPA DÖVRÜNDӘ SEREBRAL HEMODINAMIKA VO METABOLIZMIN REORQANIZASIYYASININ YAŞ XÜSUSIYYYOTLORİ}

\author{
${ }^{1}$ S.M. Kuznetsova, ${ }^{1}$ V.V. Kuznetsov, ${ }^{2}$ S.Q.Mazur \\ ${ }^{1}$ «Ukrayna MTEA-nın D.F.Çebotarev ad. Herontologiya institutu» DM, Kiyev, Ukrayna \\ ${ }^{2}$ «Ukrayna MTEA-nın Nüvə Təbabəti və Şüa Diaqnostika İnstitutu», Kiyev, Ukrayna
}

Məqalədə orta və yaşlı dövrdə işemik aterotrombotik insult keçirmiş 282 xəstənin kompleks müayinəsinin nəticələri təqdim edilir. Aşkarlanmışdır ki, orta yaşlı xəstələrdə eyni yaşlı kontrol qrupla müqayisədə serebral hemodinamikanın dəyişiklikləri yaşlı xəstələrə nəzərən daha qabarıq olmuşdur. Eyni zamanda yaşlı xəstələrdə orta yaşlı xəstələrlə müqayisədə baş beynin əsas metabolitlərinin miqdarının daha intensiv azalması xarakterdir (NAA, Cr). Yaş xüsusiyyətləri serebral hemodinamika və metabolizmin qarş1lıqlı əlaqə strukturunda da qeyd edilmişdir.

Açar sözlər: işemik aterotrombotik insult, serebral hemodinamika, metabolizm, yaş.

Redaksiyaya daxil olub: 21.04.2013

Çapa tövsiya olunub: 14.05.2013

Rəyçi: R.K.Şiraliyeva, t.e.d., prof. 